\title{
Effect of Development of Clinical Pathway on Post-operative complications for Colorectal Surgery Patients
}

\author{
Thanaa M. Diab, Sanaa M. Alaa, Mansour M. Kabbash, Mimi M. Mekkawy \& Amal M. Ahmed' \\ Assistant Lecturer of Adult Nursing, Faculty of Nursing, Aswan University, Egypt. \\ Professor of Adult Nursing, Faculty of Nursing, Alexandira University, Egypt \\ Professor of General Surgery, Faculty of Medicine, Aswan University, Egypt. \\ Professor of Adult Nursing, Faculty of Nursing, Assuit University, Egypt \\ Assistant Professor of Adult Nursing, Faculty of Nursing, Aswan University, Egypt.
}

\begin{abstract}
Colorectal surgery is associated with sizeable morbidity and, for emergency surgery, considerable mortality. Clinical pathways ensure consistency in the management of patients by their streamlined approach to patient care. Aim: The present study aimed to determine the effect of the development of clinical pathway on post-operative complications for colorectal surgery patients. Materials: A quasi- experimental research design was utilized to fulfill the aim of this study. Data were collected from general surgery department and cancer institute at Aswan governorate. Sample: Patients admitted in general surgery department who had undergone colorectal surgery 60 patients were included in the study (30 patients in the study group and 30 patients in the control group), the mean age of the study group and control group was $(52.1 \pm 6.5 \& 49.7 \pm 4.7)$ years respectively. Tools: (1) Perioperative colorectal surgery patient assessment, (2) Clinical pathway variances assessment. Conclusion: Significant difference was observed between study and control group as regard hospital length of stay also significant difference was found between the study and control groups in relation to occurrence of postoperative complications. The study Recommended that, colorectal surgery clinical pathway be used rather than the traditional delivery of care
\end{abstract}

Key words: Colorectal surgery \& Clinical pathway.

\section{Introduction}

Colorectal surgery represents a high number of patients treated at a department of gastrointestinal surgery and is not limited to cancer. It includes other non-neoplastic pathologies such as inflammatory bowel disease, diverticular disease or colonic volvulus. (Tovar,2010)

As with any major procedure, colon surgery patients may present serious or even fatal complications. The incidence of postoperative complications from colon surgery has been estimated at between $10 \%$ and $30 \%$ according to selected series. (Kehlet,2012)

Potential risks of colorectal surgery are mainly those of any major abdominal surgery, and usually occur while the patient is still in the hospital. Because of the many indications for and the various extents of colorectal or small bowel resections the rate and spectrum of complications differ. (Clavien, 2012). The most frequent postoperative surgical complications after colorectal resections are surgical site infection, anastomotic leakage, intra-abdominal abscess, ileus and bleeding. These complications have different influences on outcome and have to be diagnosed accurately. In order to meet certain quality standards it is essential to assess postoperative complications. (Kirchhoff et al., 2010).
Clinical pathways (CPWs) aim to link evidence to practice for specific health conditions and, therefore, optimize patient outcomes and maximize clinical efficiency. For the purpose of this review CPWs are defined as structured multidisciplinary care plans which detail essential steps in the care of patients with a specific clinical problem. They support the translation of clinical guidelines into local protocols and clinical practice. Whilst clinical guidelines provide generic recommendations, clinical pathways detail the local structure, systems and time-frames to address these recommendations. (Rotter, 2010)

\section{Aim of the study}

The aim of this study was

Determine the effect of the development of clinical pathway on post-operative complications for colorectal surgery patients.

\section{Research hypotheses}

Patients on whom the clinical pathway was developed exhibit less complications than those on whom it not developed.

Significance of the study

It was the first study which made in this geographical location. As colorectal surgery carries significant morbidity and mortality, which is 
associated with an enormous use of healthcare resources. So applying clinical pathway lead to better postoperative outcomes and decreases incidence of complications.

\section{Patients \& Methods}

\section{Research design:}

A quasi- experimental research design was utilized to fulfill the aim of this study.

\section{MATERIALS}

\section{Setting}

The study was conducted, in general surgery

department and cancer institute at Aswan

Governorate

\section{Subjects}

Patients admitted in general surgery department who had undergone colorectal surgery. 60 patients were included in the study it was divided in to two groups (30 for each). The study group were 30 patients who had received the developed clinical pathway, while the control group 30 patients who received routine hospital care. The mean age of the study group and control group was $(52.1+6.5 \& 49.7+4.7)$ years respectively. The patients included were able to communicate and without vital organ failure. Patient with past history of cancer at other organ were excluded from the study.

\section{Study tools}

Two tools were used for data collection

Tool 1: Perioperative colorectal surgery patient Assessment:

This tool is an interview schedule constructed by the researcher after reviewing the related literatures to assess colorectal surgery patients at the pre, intra \& post-operative period. This tool was divided into two parts to cover the following dimensions: patient profile, medical data, the patient history, current medication usage, laboratory investigations, diagnostic procedures, physical assessment, physical examination\& duration of operation, occurrence of bleeding and vital signs and post-operative assessment. These data were collected through an interview; by taking history and assessment of patients. This tool includes questions in the form of multiple choice and others in the form of yes or no questions and included the following parts:

Part (I): Pre- operative colorectal surgery assessment:

This part was developed to assess the following:

In the preoperative phase

Patients profile, patient history, risk factors, current medication usage,

laboratory investigation, diagnostic studies, physical assessment, and

physical examination

\section{In the postoperative phase}

Post-operative pain assessment, wound assessment, stoma assessment, post-operative surgical complications, and post-operative medical complications

Tool (2): Clinical Pathway Variances Assessment Tool:

This tool was developed by the researcher based on reviewing of the related literature (Townsend, 2009), (Rothrock 2010), (Tierney, 2011), \& (Patel, 2012) it aimed to measure variations of performance. Observations of performance were checked while patient care was rendered. It was applied to the study group in a form of observational checklist related to the items of patients' care which are physical preparation, providing emotional support, colostomy care, patient teaching, pain management, activity and discharge planning and prevention of complications

Scoring system

Variations of clinical pathway performance were checked according to the researcher's observations on 2 points likert scale. The score ranged from one to three with a total score value ranging between 10-30, as follows:

- Two equal to "done adequately" if the activity followed safe, complete, accurate step and performed on time, with the required frequency.

- One equal to "not done" if the activity was not performed.

\section{Method}

Written approval

A written approval was obtained from the administrative personnel at the study settings after explanation of the purposes.

\section{Testing of validity}

Content validity was done for the six developed tools. The content validity was submitted to a 7 jury members: Five professors from Assuit Faculty of Nursing and two professors from Assuit Faculty of Medicine.

Every jury member was informed about the aim of the study; they reviewed the developed tools and after consensus necessary modifications were carried out.

\section{Testing of reliability}

The reliability of assessment tools were tested using Cornbrach $^{\text {ee }} \mathrm{s}$ alpha as follows ( $\mathrm{r}=$ Perioperative colorectal surgery patient assessment tool: (0.845.), \&Clinical Pathway Variances observation checklist Assessment: (0.874)

\section{Ethical Considerations}

The researcher introduced himself to every patient including in the study, explained the purpose of the study. Patient's written Informed consent to participate in the study was then obtained. Every 
patient was informed that anonymity, confidentiality and privacy will be assured.

\section{Pilot study}

Six patients $(10 \%)$ were selected conveniently to check and ensure clarity, applicability, and feasibility of the tools and to identify the difficulties that might be faced during the application. Necessary modifications were carried out accordingly.

\section{Data collection:}

Data was collected for a period of 12 months, from May 2014 to the end of May 2015.

Development of colorectal surgery clinical pathway

Clinical pathway for colorectal carcinoma, this tool was developed by the researcher after extensive review of related literatures (Aledo, 2011) this tool was applied on the study group.

Phase one: Assessment of the Current Practice:

- Study of hospital routine as baseline for clinical pathway development:

The researcher observed nurses performance related to pre and post colorectal surgery care in oncology surgery unit for a period of one month before the establishing clinical pathway in the pre and postoperative period:

- Data collection of the control group:

Data collection started with control group who were managed according to hospital routine. Preoperative assessment of every patient in control group was done preopratively using (Tool I part I ) "Perioperative Colorectal Surgery Patient Assessment" part I "Preoperative Assessment" at general surgery department and cancer institute in the preoperative period. Subsequent using tool I part II " Post operative assessment" was utilized by the researcher daily for 4 days post -operative at general surgery department and cancer institute in order to evaluate patient's health outcomes.

Phase two: Clinical pathway development:

The researcher prepared a colorectal surgery clinical pathway template which starts with patients' profile, medical data, in addition to the clinical pathway team's role. The tool format was prepared in a matrix form that included eight vertical columns representing time intervals and seven horizontal rows representing patient's care items.

Content validity of clinical pathway was done by 7 experts in medical surgical nursing, colorectal surgery, and necessary modifications were done.

Phase three: Clinical pathway implementation and data collection of the study group:

Data collection from the study group who were subjected to the clinical pathway implemented by the researcher was carried out after completion of control group data collection.

\section{Phase four: Clinical Pathway Evaluation Statistical Analysis}

Evaluating the clinical pathway: it consisted of comparing the outcomes of both groups by using Tool one and Tool Two in relation to (postoperative pain relief, post- operative complications as anastmosis leakage paralytic ileus, respiratory complications, \&length of hospital stay,

After data were collected and transferred into specially design formats, so as to be suitable for computer feeding. Data were analyzed using PC with statistical Package for Social Sciences (SPSS) version 20.

\section{A- Descriptive statistics}

- Count and percentage: Used for describing and summarizing Categorical variables

- Mean and standard deviation: Used for describing and summarizing continuous variables.

\section{B- Analytical statistics:}

- Cronbach's Alpha reliability test:

It was used to measure the reliability of the developed tools. Its maximum value is $(\alpha=1.0)$ and the minimum accepted value is $(\alpha=0.7)$; below this level the tool would be unreliable.

- Chi-square test $\left(\chi^{2}\right)$ and fisher exact test: used to compare between categorical variables.

- t-test Test: used to compare between continuous variables.

- $5 \%$ level of significant was chosen where $\mathrm{p} \leq 0.05$ was considered significant and p>0.05 was considered as non- significant.

- The data were tested for normality using the Anderson-Darling test and for homogeneity variances prior to further statistical analysis.

- A two-tailed $\mathbf{p}<\mathbf{0 . 0 5}$ was considered statistically significant. All analyses were performed with the IBM SPSS 20.0 software.

Graphical presentations

Pie charts and bar graphs were drawn for data visualization of study and control findings using Microsoft Excel. 


\section{Results}

Table(1): Frequency and percentage distribution of the study and control group as regards patient profile $(n=60)$.

\begin{tabular}{|c|c|c|c|c|}
\hline \multirow[t]{2}{*}{ Patient profile } & \multicolumn{2}{|c|}{$\begin{array}{c}\text { Control group } \\
\mathbf{n}=\mathbf{3 0}\end{array}$} & \multicolumn{2}{|c|}{$\begin{array}{c}\text { Study group } \\
\mathbf{n}=\mathbf{3 0}\end{array}$} \\
\hline & $\mathrm{N}$. & $\%$ & N. & $\%$ \\
\hline Age, mean \pm SD & \multicolumn{2}{|c|}{$49.7 \pm 4.7$} & \multicolumn{2}{|c|}{$52.1 \pm 6.5$} \\
\hline \multicolumn{5}{|l|}{ Sex } \\
\hline Male & 18 & 60.0 & 15 & 50.0 \\
\hline Female & 12 & 40.0 & 15 & 50.0 \\
\hline \multicolumn{5}{|l|}{ Educational level } \\
\hline Illiterate & 12 & 40.0 & 18 & 60.0 \\
\hline Reading and writing & 3 & 10.0 & 3 & 10.0 \\
\hline Primary school & 3 & 10.0 & 0 & 0.0 \\
\hline Preparatory school & 0 & 0.0 & 3 & 10.0 \\
\hline Secondary school & 12 & 40.0 & 0 & 0.0 \\
\hline University & 0 & 0.0 & 6 & 20.0 \\
\hline
\end{tabular}

Table(2): Assessment of preoperative potential risk factors for study and control group $(n=60)$.

\begin{tabular}{|c|c|c|c|c|}
\hline \multirow[t]{2}{*}{ Nutritional status } & \multicolumn{2}{|c|}{ 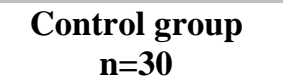 } & \multicolumn{2}{|c|}{$\begin{array}{c}\text { Study group } \\
\mathbf{n}=\mathbf{3 0}\end{array}$} \\
\hline & N. & $\%$ & N. & $\%$ \\
\hline Under weight & 15 & 50.0 & 15 & 50.0 \\
\hline Desirable & 12 & 40.0 & 6 & 20.0 \\
\hline Over weight & 3 & 10.0 & 9 & 30.0 \\
\hline Diabetes & 6 & 20.0 & 3 & 10.0 \\
\hline Hypertension & 0 & 0.0 & 3 & 10.0 \\
\hline Kidney failure & 0 & 0.0 & 0 & 0.0 \\
\hline Anemia & 12 & 40.0 & 9 & 30.0 \\
\hline COPD & 3 & 10.0 & 0 & 0.0 \\
\hline \multicolumn{5}{|l|}{ Current medication usage } \\
\hline Steroids & 3 & 10.0 & 0 & 0.0 \\
\hline Chemotherapy & 9 & 30.0 & 6 & 20.0 \\
\hline Radiation therapy & 3 & 10.0 & 3 & 10.0 \\
\hline
\end{tabular}

Table (3): Comparison between the study and control group as regards post-operative wound and stoma assessment.

\begin{tabular}{|l|c|c|c|c|c|}
\hline \multirow{2}{*}{} & \multicolumn{2}{|c|}{$\begin{array}{c}\text { Control group } \\
\mathbf{N = 3 0}\end{array}$} & \multicolumn{2}{c|}{$\begin{array}{c}\text { Study group } \\
\text { n=30 }\end{array}$} & \multirow{2}{*}{ P. value } \\
\cline { 2 - 6 } & $\mathbf{N}$ & $\mathbf{\%}$ & $\mathbf{N}$. & $\mathbf{\%}$ & \\
\hline Wound assessment & 18 & 60.0 & 9 & 30.0 & $0.020^{*}$ \\
\hline Pain or tenderness & 15 & 50.0 & 3 & 10.0 & $0.001^{* *}$ \\
\hline Localized swelling & 12 & 40.0 & - & - & $0.000^{* *}$ \\
\hline Hotness & 12 & 40.0 & - & - & $0.000^{* *}$ \\
\hline Redness & 9 & 30.0 & - & - & $0.001^{* *}$ \\
\hline Purulent discharge & 9 & 30.0 & - & - & $0.001^{* *}$ \\
\hline Delayed healing & 9 & 30.0 & - & - & $0.001^{* *}$ \\
\hline Offensive wound exudates & 6 & 40.0 & - & - & $0.031^{*}$ \\
\hline Dehiscence & & & & & \\
\hline
\end{tabular}




\begin{tabular}{|l|c|c|c|c|c|}
\hline \multirow{2}{*}{} & \multicolumn{2}{|c|}{$\begin{array}{c}\text { Control group } \\
\mathbf{N = 3 0}\end{array}$} & \multicolumn{2}{c|}{$\begin{array}{c}\text { Study group } \\
\text { n=30 }\end{array}$} & \multirow{2}{*}{ P. value } \\
\cline { 2 - 5 } & $\mathbf{N}$. & $\mathbf{\%}$ & $\mathbf{N}$. & \% & \\
\hline Stoma assessment & 15 & 50.0 & 15 & 50.0 & 1.000 \\
\hline Slight edema & 3 & 10.0 & 0 & 0.0 & 0.202 \\
\hline Bleeding & 0 & 0.0 & 0 & 0.0 & - \\
\hline Necrosis & 6 & 20.0 & 0 & 0.0 & $0.032^{*}$ \\
\hline Stoma retraction & 6 & 20.0 & 3 & 10.0 & 0.121 \\
\hline Skin irritation & \multicolumn{7}{|l|}{} \\
\hline
\end{tabular}

N.B: $-=0$

Table (4):Relation between the application of clinical pathway and post-operative paralytic ileus.

\begin{tabular}{|l|c|c|c|c|c|}
\hline \multirow{2}{*}{} & \multicolumn{2}{|c|}{ Control group } & \multicolumn{2}{|c|}{ Study group } & \multirow{2}{*}{ P. value } \\
\cline { 2 - 5 } & N. & \% & N. & \% & \\
\hline Paralytic ileus & 6 & 20.0 & - & - & $0.010^{* *}$ \\
\hline
\end{tabular}

Statistically significant difference $(p=0.01)$

Table (5): Relation between the application of clinical pathway and post-operative wound infection $(n=60)$.

\begin{tabular}{|l|c|c|c|c|c|}
\hline \multirow{2}{*}{} & \multicolumn{2}{|c|}{ Control group } & \multicolumn{2}{|c|}{ Study group } & \multirow{2}{*}{ P. value } \\
\cline { 2 - 6 } & $\mathbf{N}$. & $\mathbf{\%}$ & $\mathbf{N}$. & $\mathbf{\%}$ & \\
\hline -Wound infection & 6 & 20.0 & - & - & $0.031^{*}$ \\
\hline
\end{tabular}

Table (6): Relation between the application of clinical pathway and hospital length of stay.

\begin{tabular}{|l|c|c|c|c|c|}
\hline \multirow{2}{*}{} & \multicolumn{2}{|c|}{ Control group } & \multicolumn{2}{|c|}{ Study group } & \multirow{2}{*}{ P. value } \\
\cline { 2 - 5 } & $\mathbf{N}$. & \% & N. & \% & \\
\hline Hospital length of stay & \multicolumn{2}{|c|}{$13.7 \pm 7.4$} & \multicolumn{2}{|c|}{$8.8 \pm 3.1$} & $0.001 * *$ \\
\hline
\end{tabular}

Statistically significant difference $(p<0.001)$

Table(1): Characteristics of patients under the study: the data reveals that the mean age of the study group was $(52.1 \pm 6.5)$, half of them $(50 \%)$ were male and more than half of them $(60 \%)$ were illiterate. While in control group the mean age was $(49.7 \pm 4.7)$, more than half of them were male $(60 \%),(40 \%)$ were illiterate, $(40 \%)$ were secondary school, $(10 \%)$ were reading \& writing and $(10 \%)$ were primary school.

Table(2): Distribution of the study and control group regarding preoperative potential risk factors for study and control group, half of patients in both study and control groups were under weight, $(20 \%$ and $40 \%$ ) of both study and control groups respectively had desirable weight and there were increase in the percentage of obese patients in the study group than the control one (30\% and $20 \%$ ) respectively. As well, the highest percentage $(30.0 \%)$ in study group have anemia and $(10 \%)$ have diabetes and hypertension and in control group were (40\%) of patients have anemia, (20\%) have diabetes.

Table(3): Demonstrated that, more than half of patients of control group $(60.0 \%)$ and $(30 \%)$ of the study group had experienced pain and tenderness and one half of the control group had localized swelling in relation to hotness, redness, purulent discharge, delayed healing, \& dehiscence, the highest percentage were in the control group (40\%, $40 \%, 30 \%, 30 \%, 30 \%, \& 40 \%$ ) and $0 \%$ of the study group with statistical significant differences between study and control group regarding wound assessment. Considering stoma assessment half of patients of control group and study group had experienced slight edema. The data also revealed that increased percentage of bleeding, Stoma retraction, \& Skin irritation were in the control group than the study one. $(10 \%, 20 \%, 20 \%)$ of the control group versus $(0 \%, 0 \% \& 10 \%$ of the study group) with statistical significant differences between study and control group in relation to stoma retraction $(\mathrm{P}=0.032 *)$.

Table(4): Presented significant difference between study and control group as regard paralytic ileus $(\mathrm{P}=.010)$ 
Table (5): Had showen that significant difference was observed between study and control group as regard wound infection $((\mathrm{p}=.031)$

Table (6): Revelead that significant difference was observed between study and control group as regard hospital length of stay $\mathrm{P}=0.001$.

\section{Discussion}

The findings of the present study revealed that there were no statistical significant differences in the basic data (patient's age \& sex) between the control and study groups. while highly significant difference was observed between the study and control group related to the educational level at the beginning of the study.

Concerning gender, the present study showed that more than half the control groups were male, this finding in the line with those of Ferlay, (2013) who mentioned that the incidence of CRC for women is lower than that for men worldwide, although there is some geographical variation. As well, Oberoi, (2014) mentioned that men are known to have increased risk, higher incidence and worse prognosis for CRC than women. Men are more likely than women to develop $\mathrm{CRC}$ at all ages. Furthermore this finding was also agree with that of Weige et al., 2009 \& Lawrence, et al., (2007) who found that women are less likely than men to develop cancer, as estrogen hormone reduces the incidence of cancer in women. Collectively, estrogen appears to be protective for colorectal cancer development in women.

In relation to educational level, more than half of the study group and more than one-third of the control group were illiterate. This result is consistant with Mohammed, (2016) who mentioned the highest percentages of patients undergoing colorectal surgery in both control and study groups were illiterate and primary education. On the other side highly educated patients represented less than one fourth of the studied group and none of the control group. This result was supported by Chen et al., (2010), who mentioned that patients with higher education had high global health status. As well, Mouw et al., (2009), clarified that the higher level of educational attainment had lower cancer risk. Furthermore, the present result was explained by (Maziad, 2012, Albano, 2012 and Heleny, 2013) as they reported that, higher education levels were strongly associated with decreased cancer incidence from lung, colorectal, breast, and prostate cancers. But the groups of people with less education have higher incidence rates of cancer. Also, they added that the result may be due to increased knowledge and perception of highly educated people about the importance of early detection of cancer and selection of appropriate time for cancer treatment.

Considering preoperative potential risk factors, results revealed that

there were increased in the percentage of obese patients in the study group than the control one. On same line, this result agree with Craig \& Jennette, (2015), who reported that, one of the strongest lifestyle risk factors associated with this cancer is body mass index The International Agency for Research on Cancer concluded that $11 \%$ of colon cancer cases were caused by obesity.

The results also revealed that more than one third of the study group and more than one fourth of the control group had anemia this result agree with Muñoz, (2014), who stated that anemia is one of the most frequent extra intestinal manifestations of colorectal cancer (CRC).

As regard the relation between the application of clinical pathway and postoperative ileus results revealed increased percentage of patients who had experienced paralytic ileus during the postoperative day-1 and day- 2 in the control group than the study one with significant difference between study and control group as regard paralytic ileus. This findings agree with, Jane, (2010) who stated that postoperative complications were significantly reduced in clinical pathway patients.

Study results also show that half patients of the control group had wound infection during the postoperative day-1 and day 2 with significant difference was observed between study and control group as regard wound infection this findings come in accordance with Ishikawa, (2014) who mentioned that Surgical site infections (SSI) are the most common nosocomial infection in surgical patients, contributing to perioperative morbidity, prolonged postoperative hospital length of stay, and increased hospital costs. As well, Smith et al.,( 2009) clarified that surgery for colorectal cancer is associated with bacterial contamination and postoperative wound infections.

As regard hospital length of stay, results revealed that significant increased hospital length of stay in the control group than the study one with significant difference between the two group. This agrees with Nussbaum et al., (2014) who emphasized that hospital length of stay was shorter on patient treated with clinical pathway.

\section{Conclusion}

Implementation of clinical pathway for patients undergoing colorectal surgery exhibited significant differences in incidence of post -operative complications and hospital length of stay in patients 
going through clinical pathway and those who are undergoing hospital routine care

\section{Recommendation}

- Development and application of clinical pathways in other areas of clinical specialties.

- Evaluate the effect of development and application of clinical pathways in colorectal cancer patient undergoing various treatment modalities as chemotherapy or radiotherapy.

- Study the staff satisfaction and cost effectiveness after implementation of the clinical pathway.

\section{References}

1. Kirchhoff P., Clavien P., \& Hahnloser D., (2010): Complications in colorectal surgery: risk factors and preventive strategies. Patient Safety in $\quad$ Surgery, 4:5 http://www.pssjournal.com/content/4/1/2015

2. Hoffman R., Edmund K., Bartlett E., Clifford \& K., (2014): Early discharge and readmission after colorectal resection. YJSRE12561_proof _ 6 March 2014 _2:21 am

3. Rotter T., Kinsman L., \& James E., (2010): Clinical pathways: effects on professional practice, patient outcomes, length of stay and hospital costs, CochraneDatabase of Systematic Reviews, Issue 3. Art.No.:CD006632.

4. Aledo V., Ballester M., Franco \& E., (2011): Evaluation of a Clinical Pathway to Improve Colorectal Cancer Outcomes. American Journal of Medical Quality 26(5) 396 -404 (C) 2011 by the American College of Medical Quality Reprints and permission: http://www. sagepub.com/journalsPermissions.nav DOI: $10.1177 / 1062860611404049$ http://ajmq.sagepub.com/15/5/2014

5. Tovar J., Castiñeiras V., \& Martínez E., (2010): Postoperative complicactions of colon surgery. Volume 78, No. 3, May-June 281

6. Ishikawa K, Kusumi T, Hosokawa M, Nishida Y, \& Sumikawa S., (2014): Incisional Surgical Site Infection after Elective Open Surgery for Colorectal Cancer. Int J Surg Oncol: 419712.

7. Craig A., \& Jennette P., (2015): Lifestyle Modification: A Primary Prevention Approach to Colorectal Cancer. American Journal of Lifestyle Medicine. vol. $6 \cdot$ no. 3

8. Munoz M., Ramirez S., Montanez E., \& Auerbach M., (2014): Perioperative anemia management in colorectal cancer patients: A pragmatic approach. World J Gastroenterol.
9. Clavien P., Barkun J., de Oliveira M., (2012): The Clavien-Dindo classification of surgical complications: five-year experience. Ann Surg, 250:187-196.

10. Agency for Healthcare Research \& Quality, Rockville, (1992): Acute Pain Management: Operative or Medical Procedures and Trauma, Clinical Practice Guideline No. 1. AHCPR Publication No. 92-0032; February 1992. MD; pages 116-117.

11. Kehlet H., ( 2012): Fast track colorectal surgery. Lancet;371:391-393.

12. Smith R., Bohl J., \& Mcelearney S., (2009): Wound infection after elective colorectal resection. Ann Surg 239:599-607

13. Jane, J., \& Tan, \& Angel Y., (2010): Colorectal Clinical Pathways: A Method of Improving Clinical Outcome? [Asian J Surg;28(4):252-6])

14.Amr E., (2014): The Effect of Clinical Pathway Implementation on Healing of Post Lower Limb Amputation for Diabetic Patients. Alexandria University. Faculty of nursing. Unpublished doctor thesis.

15. Oberoi, D., Jiwa M., \&McManus A., (2014): Colorectal cancer - applying a gender lens, Quality in Primary Care 2014;22:71-9.

16. Ferlay J., Soerjomataram I., Ervik M., (2013): Cancer Incidence and Mortality Worldwide: IARC Cancer Base No. 11 [Internet]. Lyon, France: International Agency for Research on Cancer. http://globocan.iarc.fr. Accessed on 27 Apr 2015

17. Weige C., Allred K., Allred D., Estradiol Alters Cell Growth in Nonmalignant Colonocytes and Reduces the Formation of Preneoplastic Lesions in the Colon. Cancer Research 2009; 69(8): 9118-24.

18. Mohammed N., (2014): Effect of Clinical Pathway Application on Health Outcomes of Patients Undergoing Colorectal Surgery. Alexandria University. Faculty of nursing .Unpublished doctor thesis.

19. Cheney, J., (2010): Evaluation of the effectiveness of a clinical pathway for bronchiolitis. Centre for Nursing Research.

20. Mouw T., Koster, A., \& Wright, M., (2009): Educational and risk of cancer in a large cohort of men and women. Available at: http: //www. plosone. org/ article/ info\% 3Adio\% journal. pone.0003639.

21. Maziad A., ( 2012): Knowledge of Patients with Prostate Cancer Receiving Hormonal Therapy. Alexandria University. Faculty of Nursing. Unpublished Thesis

22. Albano J., Ward E., Jemal A., (2012): Association between Cancer Incidence and Level 
of Education. British Journal of Cancer; 15(4): 381-8.

23. Henley J., Liff J., Thun M., ( 2013): Cancer Mortality in the United States by Education Level and Race. Journal of the National Cancer Institute; 99 (18): 1384-94. 